\title{
His bundle recordings in right bundle-branch block coexisting with iatrogenic right ventricular pre-excitation
}

\author{
Agustin Castellanos, Jr. and Cesar A. Castillo \\ From the Section of Cardiology, Department of Medicine, University of Miami School of \\ Medicine, and the Cardiopulmonary Laboratory, Veterans Administration Hospital, Miami, \\ Florida, U.S.A.
}

Iatrogenic right ventricular pre-excitation failed to abolish right bundle-branch block in two patients. When 'exclusive' His bundle pacing was performed, the QRS complexes, St-V, and $S t-L V E$ intervals were similar to the ventricular deflections, $H-V$, and $V-L V E$ (intervals) recorded during sinus rhythm. 'Exclusive' pacing of the ordinary muscle at the right ventricular inflow tract produced a complete left bundle-branch block pattern without abnormal left axis deviation. Pacing of both His bundle and ordinary muscle yielded combination complexes in which the right bundle-branch block pattern persisted.

The ventricular activation process was studied in these beats, as well as during the right and left bundle-branch block induced by coupled atrial stimulation. It appeared as if certain areas of the right septal surface behaved, electrophysiologically, as if they belonged to the left ventricle. Impulses emerging from these sites were not propagated to the right ventricular free wall. The latter was activated by the excitation front emerging through the left bundle system. During right bundle-branch block the endocardium of the right ventricular inflow was activated before the peak of the $R$ in $V_{1}$. Bipolar leads, I mm apart (with the possible exception of the ones over the tricuspid valve), were helpful in mapping the spread of activation in the human heart.

There are conflicting views on whether right bundle-branch block can coexist with right ventricular pre-excitation (Wolff-ParkinsonWhite type B). The experimental work of Gamboa et al. (1962) seemed to indicate that this association could not occur. However, other authors have reported it (Cabrera, Feldman, and Olinto, 1959; Robertson et al., 1963; Zakopoulos, Tsatas, and Liokis, 1964). In view of these discrepancies it appeared of interest to present the information obtained from two patients with right bundle-branch block in which right ventricular pre-excitation was induced by electrical stimulation, while intracardiac and His bundle electrograms were recorded.

\section{Material and methods}

Technique of His bundle recordings The technique of His bundle recordings used in our department has been described in previous communications (Castellanos et al., 1970a; Castellanos, Castillo and, Myerburg, 1971).

After obtaining consent, a tripolar catheter

Received 22 March 197 I. electrode ${ }^{1}$ was introduced percutaneously through the femoral vein, and positioned across the septal leaflet of the tricuspid valve under fluoroscopic control to obtain a His bundle electrogram. This electrode catheter had three poles, two separated by a I $\mathrm{mm}$ distance (His bundle electrogram ${ }_{1}$ ) and the third pole II $\mathrm{mm}$ from the first (His bundle electrogram ${ }_{11}$ ). Two additional bipolar electrode catheters with I $\mathrm{mm}$ interelectrode distances ${ }^{1}$ were introduced percutaneously through an antecubital vein. One of them was placed in the high right atrium (bipolar atrial electrogram). The other catheter was introduced into the great cardiac vein through the coronary sinus (bipolar coronary sinus electrogram), from where it recorded a local left ventricular electrogram at the postero-superior portions of the corresponding ventricle. The electrode leads were fed into a distribution switch-box capable of obtaining any desired combination. The outputs of the distribution switch-box were connected to the input of conventional electrocardiographic amplifiers and the signals filtered below $40 \mathrm{~Hz}$ and above $500 \mathrm{~Hz}$. A fourth bipolar catheter electrode with the same interelectrode distance was also introduced in the same fashion for intracardiac pacing. Recording of the three standard peripheral leads and a VI 1 Elecath Corporation, New Jersey. 
praecordial lead was carried out simultaneously with the intracavitary electrograms of the corresponding sites, using an oscillographic multichannel recorder ${ }^{1}$ at paper speeds of 50 or 100 $\mathrm{mm} / \mathrm{sec}$.

Measurements performed The following intervals were measured and the results expressed in msec: (a) PR: as in conventional electrocardiography; (b) HRA-LRA: from the beginning of the $P$ wave in the surface electrocardiogram, or in the bipolar atrial electrogram lead, to the local atrial electrogram in the His bundle electrogram lead; (c) LRA-H: from the local atrial electrocardiogram in the His bundle electrogram lead to the $\mathbf{H}$ deflection in the same lead; (d) $\mathrm{H}-\mathrm{V}$ : from the $\mathbf{H}$ deflection to the onset of ventricular depolarization, in whichever lead it occurred first; (e) St-V (during His bundle pacing): from the emission of the spike to the onset of ventricular depolarization; (f) $\mathrm{H}-\mathrm{LVE}$ : from the $\mathrm{H}$ deflection to the local ventricular electrogram in the coronary sinus bipolar lead (CSBE) lead;(g) St-LVE (during His bundle pacing): from the spike to the local ventricular electrogram in the CSBE lead; (h) V-LVE: from the beginning of the QRS complex to the local ventricular electrogram in the CSBE lead.

During right ventricular endocardial pacing the emission of the spike was considered as the beginning of the QRS complex.

Technique for His bundle pacing To perform His bundle pacing the terminals (corresponding to the II $\mathrm{mm}$ apart bipolar leads) of the catheter recording the $\mathrm{His}$ bundle electrogram were connected to an external pacemaker. The latter delivered slightly underdamped impulses of 2.5 msec duration. The intensity used was twice that of one required for right ventricular apical pacing. His bundle deflections were not observed during this procedure since they were obscured by the stimulus artefact. Therefore, the following criteria had to be used for the diagnosis of 'exclusive' His bundle pacing: (a) St-V and St-LVE intervals similar to the $\mathrm{H}-\mathrm{V}$ and $\mathrm{H}-\mathrm{LVE}$ intervals recorded during sinus rhythm, and (b) QRS complexes identical to the one induced by the sinus P waves (Narula, Scherlag, and Samet, 1970; Puech et al., 1970; Coumel et al., 1970). In all cases in which His bundle pacing was attempted there were periods of time during which the stimulus activated 'exclusively' the ordinary myocardium of the right ventricular inflow tract. On other occasions the latter was paced simultaneously with the His bundle, resulting in a QRS complex of intermediate contour. This variable response to stimulation of the $H$ is bundle area was also observed by Puech et al. (1970) and Coumel et al. (1970).

\section{Case reports}

Two patients with right bundle-branch block were studied. In addition, one had left anterior hemiblock and the other left posterior hemiblock (Rosenbaum, Elizari, and Lazzari, 1968).

1 Electronics for Medicine.
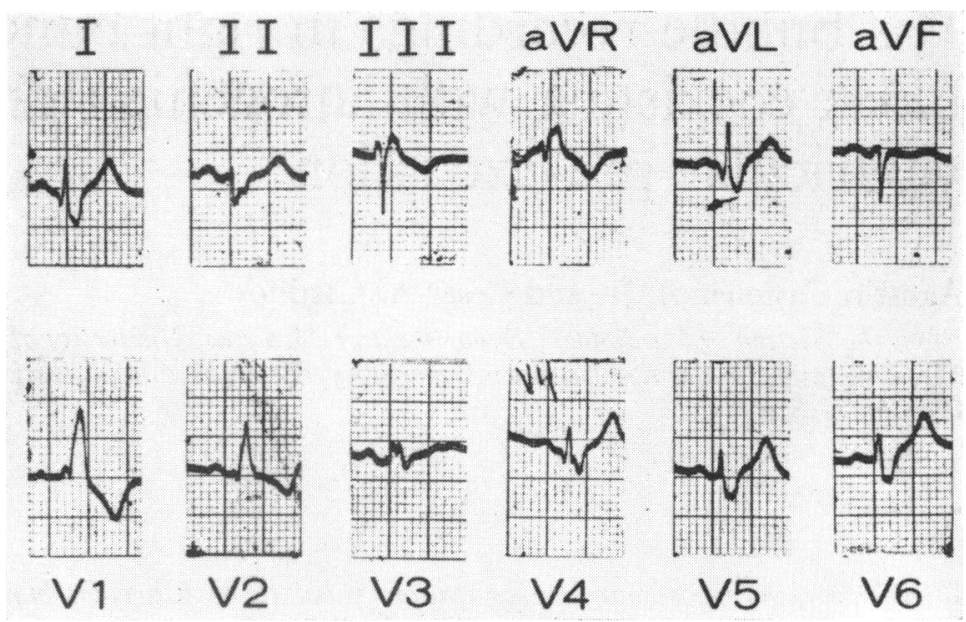

FIG. I (Case I) Complete right bundlebranch block and abnormal left axis deviation due to left anterior hemiblock.

FIG. 2 (Case I) Sinus rhythm (left). His bundle pacing (centre), and right ventricular apical pacing (right). BAE: bipolar atrial electrogram recording the electrical activity of the high right atrium (HRA); HBE: His bundle electrogram recording the electrical activity of the low right atrium (LRA), His bundle $(H)$, and ordinary muscle of the right ventricular inflow tract; BCSE: bipolar coronary sinus lead recording the electrogram of the posterosuperior left ventricular wall (LVE); St: pacemaker stimulus artefact. All intervals are defined in the text. Paper speed was $100 \mathrm{~mm} / \mathrm{sec}$.

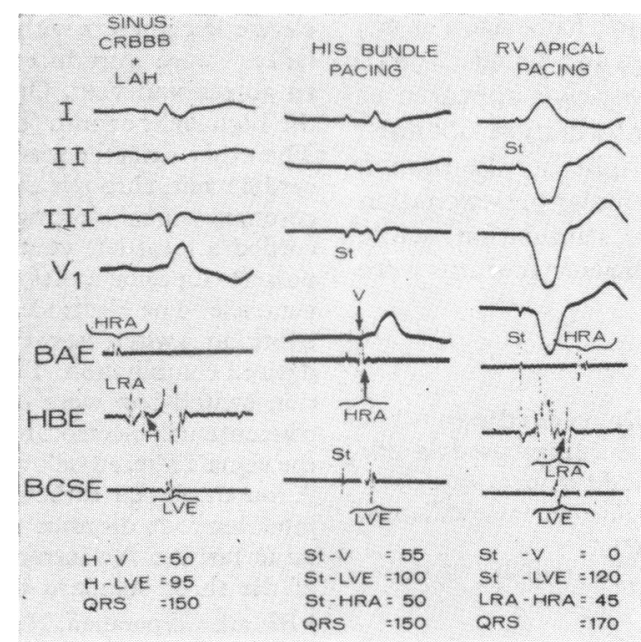


Case I This 63-year-old patient was referred to the Cardiopulmonary Laboratory for the insertion of a temporary pacemaker. He had suffered several syncopal attacks in the week before admission. Intracardiac recordings and His bundle electrograms were obtained to evaluate the nature of the conduction disturbances.

The control electrocardiogram showed right bundle-branch block and abnormal left axis deviation due to left anterior hemiblocks (Fig. I). The PR interval measured $150 \mathrm{msec}$. The duration of the most significant intervals in this patient during sinus rhythm was as follows: (Fig. 2, left panel): (a) PR: I50 msec, (b) HRA-LRA: $40 \mathrm{msec}$, LRA-H: 60 msec, H-V: 50 msec, H-LVE: 95 msec, and QRS complexes: $150 \mathrm{msec}$. The V-LVE interval measured $45 \mathrm{msec}$, hence the posterosuperior regions of the left ventricle were activated $45 \mathrm{msec}$ after the beginning of the QRS complex. The presence of a normal $q$ wave in leads I, aVL, and V6 indicated that ventricular depolarization started in the left ventricle.

During His bundle pacing (Fig. 2, middle panel) the St-V and St-LVE intervals, as well as the QRS complexes, had a duration similar to the $\mathrm{H}-\mathrm{V}$ and $\mathrm{H}-\mathrm{LVE}$ intervals observed during sinus rhythm. In addition, the duration of the StHRA interval and the LRA-HRA interval recorded in beats with retrograde (V-A) conduction was the same (right sided panel in Fig. 2). This finding suggested that, during His bundle pacing, the low right atrium was also stimulated 'directly' (Coumel et al., 1970). In other words, the retrograde $\mathbf{P}$ wave did not result from a stimulus propagating backwards from the His bundle through the AV node, for otherwise the St-HRA interval would have measured $100 \mathrm{msec}$, the value representing the addition of $60 \mathrm{msec}$ (H-LRA interval) and $40 \mathrm{msec}$ (LRA-HRA interval).

The right-sided panel in Fig. 2 was recorded during right ventricular apical pacing. The resulting QRS complex showed a complete left bundlebranch block pattern with abnormal left axis deviation. There was a 120 msec interval between the delivery of the stimulus to the right ventricular apical endocardium and the moment in which the posterosuperior site exploring the bipolar coronary sinus lead was activated.

The first beat in Fig. 3 was of sinus origin. The second QRS complex resulted from 'exclusive' activation of the ordinary myocardium at the right ventricular inflow tract. It showed a complete left bundle-branch block pattern with a normal ÂQRS and no evidence whatsoever of right bundle-branch block. The St-LVE interval measured 130 msec because of delayed activation of the left ventricle. In contrast, the last beat was intermediate in contour between the previous ones. Though its QRS duration was slightly shorter, the direction and morphology of the initial $70 \mathrm{msec}$ vectors was similar to that of beats produced by 'exclusive' myocardial pacing. Yet, the presence of a QR pattern in VI indicated that iatrogenic right ventricular pre-excitation had not completely abolished the right bundle-branch block. The posterosuperior region of the left ven-

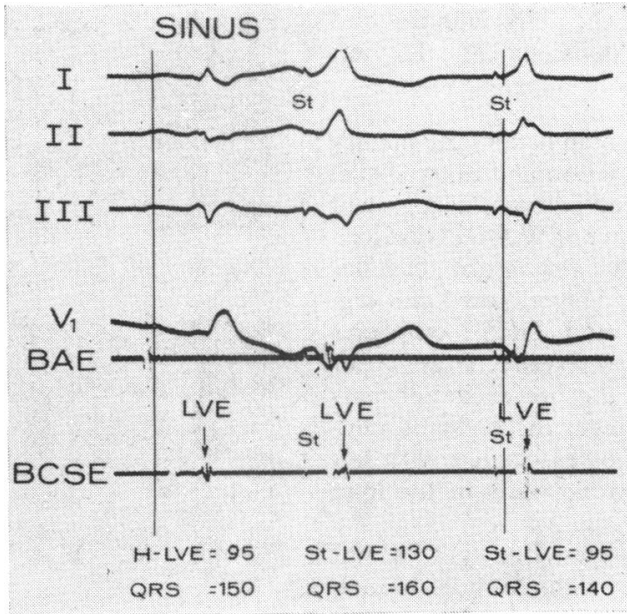

FIG. 3 (Case I) Sinus rhythm (left) exclusive pacing of the ordinary muscle of the right ventricular inflow tract (centre), and simultaneous stimulation of the latter and His bundle (right). Paper speed was $50 \mathrm{~mm} / \mathrm{sec}$.

tricle was activated $95 \mathrm{msec}$ after the emission of the spike. This value was similar to the H-LVE interval recorded during sinus rhythm, suggesting that the left ventricle was depolarized by the im-

FIG. 4 (Case 2) Electrocardiogram obtained in 1963 interpreted as simultaneous coexisting Wolff-Parkinson-White type $A$ and right bundle-branch block.

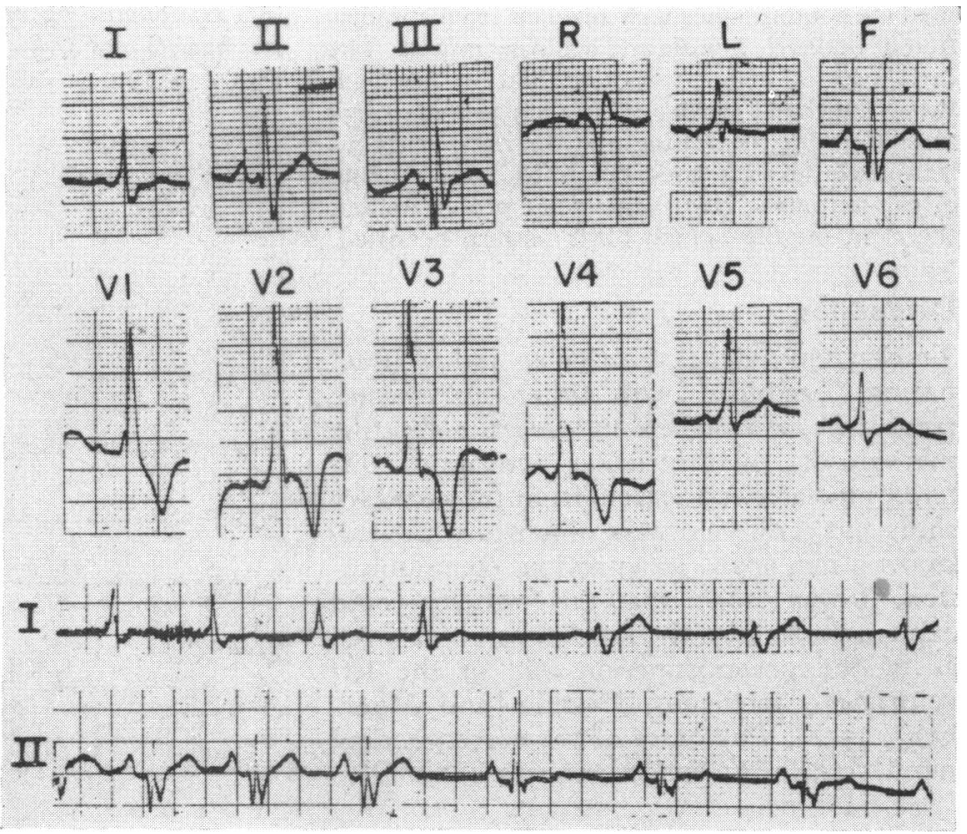


pulse propagating from the $\mathrm{His}$ bundle and emerging through the divisions of the left branch.

Case 2 This 34-year-old man had a long history of paroxysmal rapid heart action and dizzy spells. Electrocardiograms recorded in 1963 (Fig. 4) had been interpreted as suggestive of Wolff-ParkinsonWhite type $A$ associated with right bundlebranch block (Castellanos, Mayer, and Lemberg, 1962). The $P R$ interval and $Q R S$ complexes measured 130 and $150 \mathrm{msec}$, respectively. After temporary abolishment of the pre-excitation pattern by carotid sinus massage, the right bundlebranch block appeared to be associated with left posterior hemiblock (last three beats in the long strips of leads I and II in Fig. 4).

Tracings obtained in 1970 (Fig. 5) did not show pre-excitation. The right bundle-branch block pattern with right axis deviation due to left posterior hemiblock was permanent. Though this patient had a history of asthma, haemodynamic studies in the present admission showed normal right ventricular and pulmonary artery pressures. His bundle electrograms recorded during sinus rhythm, atrial pacing at progressively higher rates, and coupled or paired atrial pacing failed to disclose any evidence of pre-excitation (Castillo and Castellanos, 1970).

In this patient, exclusive His bundle pacing (Fig. 6, right) produced QRS complexes of identical morphology and duration to those of sinus beats (Fig. 6, left). In addition, the St-V and the $H-V$ intervals had similar values. The second QRS complex in Fig. 7 was produced by 'exclusive' pacing of the ordinary muscle at the right ventricular inflow tract. It showed a complete left bundle-branch block pattern without abnormal left axis deviation. The third beat in Fig. 7 and the second QRS complex in Fig. 6 had an intermediate contour since they resulted from stimulation of both His bundle and ordinary muscle. The early part of depolarization (initial $70 \mathrm{msec}$ ) in these beats had a similar orientation as in exclusive muscle pacing, indicating that the right ventricular muscle was activated before the left. In spite of the iatrogenic right ventricular pre-excitation, the right bundle-branch block pattern persisted.

\section{Discussion}

Transvenous right ventricular inflow tract pacing, combined with other intracardiac recordings, was of help in understanding the mechanisms of ventricular activation. Filtered bipolar electrograms from the coronary sinus and great vein were obtained with electrodes I mm apart. In a previous communication, it was shown that this catheter could explore portions of the low left atrium as well as of the posterosuperior wall of the left ventricle (Castellanos, Castillo, and Myerburg, 1971). The onset of the corresponding rapid ventricular deflections was believed to
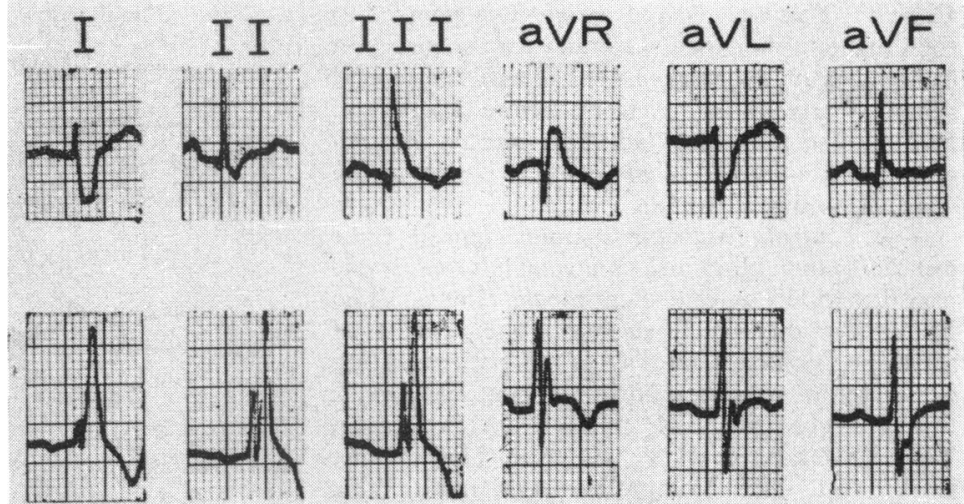

V1
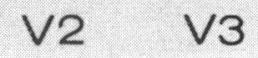

V4
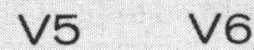

FIG. 5 (Case 2) Electrocardiogram recorded in 1970 showing right bundle-branch block with right axis deviation due to left posterior hemiblock.

indicate the moment at which the muscle close to the electrodes was activated. These assumptions were corroborated in this report. The explored left ventricular site was activated early when sinus rhythm was present (Fig. 2, left), and late during right ventricular apical and inflow tract pacing (Fig. 2 right, and Fig. 3). In both patients right ventricular inflow tract stimulation resulted in: (a) 'ex-

FIG. 6 (Case 2) Sinus rhythm (left), exclusive His bundle pacing (right), and combined His bundle and ordinary muscle pacing (centre). Paper speed was $100 \mathrm{~mm} / \mathrm{sec}$.

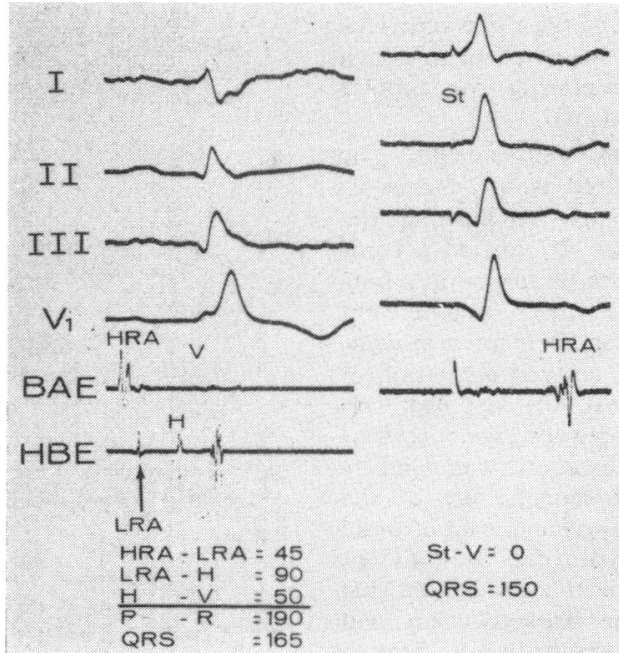




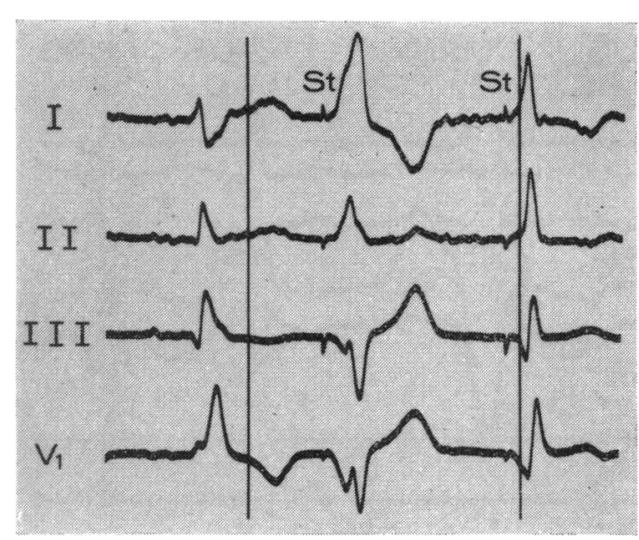

FIG. 7 (Case 2) Sinus rhythm (left), exclusive right ventricular inflow tract ordinary muscle pacing (centre), and combined stimulation of the ordinary muscle and His bundle (right). Exclusive His bundle pacing was also shown in Fig. 6 (right). In this Fig. paper speed was $50 \mathrm{~mm} / \mathrm{sec}$.

clusive' ordinary muscle pacing, (b) 'exclusive' His bundle pacing, and (c) simultaneous ordinary muscle and His bundle activation.

When sinus rhythm and right bundlebranch block were present, the late $\mathrm{R}$ in VI was produced by the left ventricular impulse. It can therefore be assumed that persistence of the $\mathbf{R}$ wave in the combination complexes shown in Fig. 3 and 7 indicated that the left ventricular impulse was still able to depolarize some parts of the right ventricle, even when other portions of the same ventricle had been pre-excited by the electrical stimulus. These beats were the iatrogenic counterpart of naturally occurring right bundle-branch block and right ventricular pre-excitation.

Gersony and Ekery (1969) explained this phenomenon by considering that the right bundle-branch block could be 'central' or 'peripheral', and related the latter to the earliest sites of pre-excitation. These authors believed that if right ventricular pre-excitation occurred proximally to the right bundlebranch block, activation of the post-block areas of the right ventricle had to occur late, since this process was then a function of the impulse originating in the left ventricle. On the other hand, the right bundle-branch morphology should disappear if pre-excitation involved the areas distal to the block. In our artificial model, pre-excitation was located proximal to the blocked site.

To speculate on the mechanisms of right bundle-branch block coexisting with right ventricular pre-excitation, it is important to understand the electrogenesis of right bundlebranch block in man. A great number of conclusions dealing with the mechanisms of this conduction defect have been derived by extrapolating from animal experiments (Boineau and Moore, 1970). For instance, a diagrammatic representation of the ventricular activation process in right bundle-branch block in three textbooks by Sodi Pallares and coworkers seems to imply that the high right septal surface and the free right ventricular wall are depolarized at more or less the same time (Sodi Pallares and Calder, I956; Sodi Pallares, Bisteni, and Medrano, r964; Sodi Pallares et al., 1970). These findings contrast with those of Erickson, Scher, and Becker (1957) and Walston et al. (1968) who observed that the endocardium of the outflow tract was activated before the free right ventricular wall. In the human heart using unipolar (intraventricular) recordings, Latour and Puech (1957) noted that activation after right ventricular outflow tract occurred before the peak of the $\mathbf{R}$ wave in VI. We have studied the sequence of

TABLE Intervals (in msec) between the beginning of depolarization and the onset of the corresponding local ventricular electrograms $\star$

\begin{tabular}{|c|c|c|c|}
\hline $\begin{array}{l}\text { Apex of } \\
\text { right } \\
\text { ventricle }\end{array}$ & $\begin{array}{l}\text { Right } \\
\text { ventricular } \\
\text { outflow tract }\end{array}$ & $\begin{array}{l}\text { Electrogram of } \\
\text { right ventricular } \\
\text { inflow tract deter- } \\
\text { mined from His } \\
\text { bundle electrogram }\end{array}$ & $\begin{array}{l}\text { Electrogram of } \\
\text { posterosuperior wall } \\
\text { of left ventricle } \\
\text { determined from the } \\
\text { bipolar coronary } \\
\text { sinus lead }\end{array}$ \\
\hline
\end{tabular}

\begin{tabular}{lrrrr}
\hline Sinus & 15 & 50 & 30 & 60 \\
Complete left bundle-branch block & 0 & 35 & 45 & 125 \\
Complete right bundle-branch block & 50 & 80 & 30 & 60 \\
Right ventricular apical pacingt & 0 & - & 50 & 120 \\
\hline
\end{tabular}

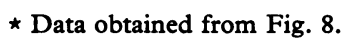

† Data obtained from Fig. 2 (right panel).

-Not measured. 
ventricular activation during sinus rhythm and bundle-branch block induced by coupled atrial pacing using I mm apart bipolar leads. A representative example is shown in Fig. 8 in which the first and third beats were of sinus origin. Coupled atrial pacing at short intervals produced atrial extrasystoles with functional block of the left branch (second beat) and of the right branch (fourth beat).

Pertinent data are shown in the Table. In the presence of normal intraventricular conduction, activation reached the right ventricular apex (vertical arrow labelled I, superimposed to the $r$ in VI) 15 msec after the onset of depolarization. The right ventricular outflow tract was activated $35 \mathrm{msec}$ later (vertical arrow labelled 2), that is, $50 \mathrm{msec}$ after the beginning of the QRS complex.

The right ventricular apex was the first area to be depolarized when complete left bundle-branch block was present. The outflow tract was activated $35 \mathrm{msec}$ later. During complete right bundle-branch block both the right ventricular apex and the right ventricular outflow tract, were depolarized with considerable delay. Activation of the right ventricular outflow tract occurred slightly ahead of the peak of the $R^{1}$ in VI, around $60 \mathrm{msec}$ before the end of the QRS complex.

These findings suggest that during normal intraventricular conduction and in complete left bundle-branch block, depolarization of the right ventricular endocardium was a function of the right branch, not of the left branch. The right ventricular apex to right ventricular outflow tract conduction times were the same in both instances. On the contrary, during complete right bundle-branch block these sites were depolarized with delay by the impulse coming from the left ventricle. Moreover, it appeared as if the free wall of the right ventricle was activated later than the right ventricular outflow tract. There was no delay in activation of the posterosuperior wall of the left ventricle in sinus beats and in those with complete right bundle-branch block, but this area was depolarized very late when complete left bundle-branch block was present.

It has to be emphasized that the results obtained with endocardial catheters (even when the leads are I mm apart) have to be interpreted with caution (Castellanos et al., 197I). In certain cases, or when the procedure is prolonged, there can be considerable catheter movements within the ventricles. In addition, the potentials recorded by these leads (I $\mathrm{mm}$ apart) are not as 'local' as the ones obtained with those specially designed for experimental studies ( 0.1 or $0.2 \mathrm{~mm}$ apart).

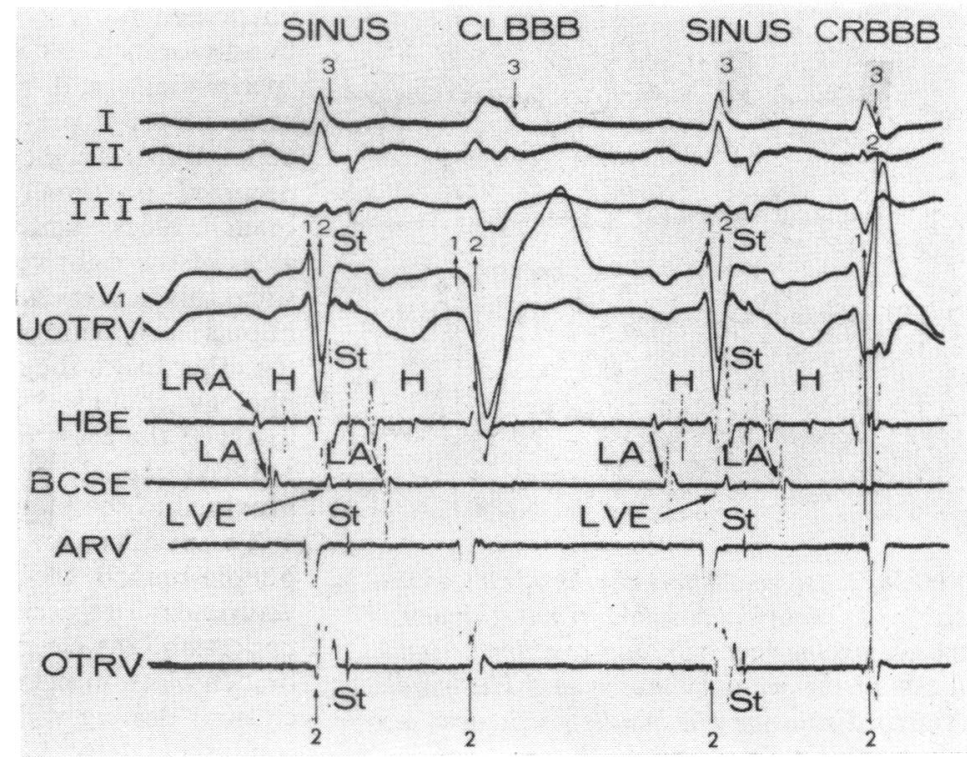

FIG. 8 (Case 3) Ventricular activation process during sinus rhythm and during bundlebranch block induced by coupled atrial pacing. Abbreviations are as follows: UOTRV: unipolar lead from the right ventricular outflow tract; $A R V$ : close bipolar lead from the right ventricular apex; OTRV: close bipolar lead from the right ventricular apex; $L A:$ local left atrial electrogram; $L V$ : electrogram from the posterosuperior wall of the left ventricle. The numbers 1,2 , and 3 indicate the moment in which the ARV, OTRV, and LVE electrogram were inscribed on leads $I$ and $V I$. Paper speed was $100 \mathrm{~mm} / \mathrm{sec}$.

If the results presented in this communication are valid, some speculations can be made regarding the mechanisms of spontaneous and iatrogenic right ventricular pre-excitation with right bundle-branch block. In both cases it appears as if the activation front emerging from the ordinary muscle of the right ventricular inflow tract does not proceed towards the free right ventricular wall, but is propagated at a slow speed through a portion of the septum in an anterior and leftward direction. This localized delay in activation is of such a degree that it gives enough time to the impulse emerging through the left bundle system to depolarize parts of the left ventricle, traverse certain areas of the septum, finally reaching the free right ventricular wall very late. A possible explanation for this paradoxical phenomenon can be found in Sodi Pallares' concepts dealing with the structure of the interventricular septum (Sodi Pallares and 
Calder, 1956). According to these authors, some parts of the septal muscle at the right ventricular inflow tract correspond, anatomically, to the left ventricle. This structural process has electrophysiological consequences. Sodi Pallares and Calder (1956) showed that in these sites there was no delay in the arrival of activation after right bundle-branch block.

We do not want to draw definite conclusions regarding the ventricular electrogram in the His bundle electrogram lead because of catheter movements produced by the tricuspid leaflets. Yet, in Fig. 8 it seemed that there was no delay in the onset of the rapid deflections in this lead after right bundle-branch block (compared with beats with normal conduction). If these assumptions are correct, they can explain why activation from this (anatomically left ventricular area) could be delayed in its journey towards the free right ventricular wall. However, more studies in the human heart are required to corroborate them.

\section{References}

Boineau, J. P., and Moore, E. N. (1970). Evidence for propagation of activation across an accessory atrioventricular connection in Types $A$ and $B$ preexcitation. Circulation, 41, 375.

Cabrera, E., Feldman, J., and Olinto, F. C. (1959). Estudio electro y vectocardiografico de un caso de Wolff-Parkinson-White con bloqueo de rama derecta. Archivos del Instituto de Cardiologia de México, 29, 404.

Castellanos, A., Jr., Castillo, C. A., and Myerburg, R. (197I). Bipolar coronary sinus lead for left atrial and left ventricular recording. American Heart fournal, 81, 832.

Castellanos, A., Jr., Chapunoff, E., Castillo, C. A., Maytin, O., and Lemberg, L. (I970a). His bundle electrograms in two cases of Wolff-ParkinsonWhite (pre-excitation) syndrome. Circulation, 4I, 399.

Castellanos, A., Jr., Mayer, J. W., and Lemberg, L. (1962). The electrocardiogram and vectorcardiogram in Wolff-Parkinson-White syndrome associated with bundle-branch block. American fournal of Cardiology, 10, 657.

Castellanos, A., Jr., Ortiz, J. M., Pastis, N., and Castillo, C. (I970b). The electrocardiogram in patients with pacemakers. Progress in Cardiovascular Disease, 13, 190.

Castillo, C. A., and Castellanos, A., Jr. (1970). His bundle recordings in patients with reciprocating tachycardias and Wolff-Parkinson-White syndrome. Circulation, 42, 271.

Coumel, Ph., Waynberger, M., Slama, R., and Bouvrain, Y. (1970). L'enregistrement de l'activite' e'lectrique du faisceau de His. Presse Médicale, 78, 365.

Erickson, R. V., Scher, A. M., and Becker, R. A. (1957). Ventricular excitation in experimental bundle-branch block. Circulation Research, 5, 5 .

Gamboa, R., Peñaloza, D., Sime, F., and Banchero, N. (I962). The role of the right and left ventricles in the ventricular pre-excitation (WPW) syndrome. An experimental study in man. American fournal of Cardiology, 10, 650.

Gersony, W. M., and Ekery, D. D. (1969). Concealed right bundle-branch block in the presence of Type B ventricular pre-excitation. American Heart fournal, 77, 668.

Latour, H., and Puech, P. (1957). Electrocardiographie Endocavitaire. Masson, Paris.

Narula, O. S., Scherlag, B. J., and Samet, P. (1970). Pervenous pacing of the specialized conducting system in man. Circulation, 4I, 77.

Puech, P., Latour, H., Grolleau, R., Dufoix, R., Cabasson, J., and Robin, J. (1970). L'activité électrique du tissue de conduction auriculo-ventriculaire en électrocardiographie intracavitaire. I. Identification. Archives des Maladies du Coeur et des Vaisseaux, 63, 500.

Robertson, P. G. C., Emslie-Smith, D., Lowe, K. G., and Watson, H. (1963). The association of type B ventricular pre-excitation and right bundle-branch block. British Heart fournal, 25, 755.

Rosenbaum, M. B. Elizari, M. V., and Lazzari, J. O. (1968). Los Hemibloqueos. Paidos, Buenos Aires.

Sodi Pallares, D., Bisteni, A., and Medrano, G. A. (1964). Electrocardiografia y Vectorcardiografia Deductivas. Prensa Medica Mexicana, Mexico City.

Sodi Pallares, D., and Calder, R. M. (1956). New Bases of Electrocardiography. Mosby, St. Louis.

Sodi Pallares, D., Medrano, G. A., Bisteni, A., and Ponce de Leon, J. (1970). Deductive and Polyparametric Electrocardiography. Instituto Nacimal de Cardiologia, Mexico City.

Walston, A., Boineau, J. P., Spach, M. S., Ayers, C. R., and Estes, E. H. (1968). Relationship between ventricular depolarization and QRS in right and left bundle-branch block. Fournal of Electrocardiology, 2, 155.

Zakopoulos, K. S., Tsatas, A. T., and Liokis, T. E. (1964). Type B Wolff-Parkinson-White syndrome associated with right bundle-branch block. Diseases of the Chest, 46, 346.

Requests for reprints to Dr. Agustin Castellanos, Jr., Section of Cardiology, Department of Medicine, School of Medicine, University of Miami, P.O. Box 875, Biscayne Annex, Miami, Florida 33152, U.S.A. 